\title{
KUALITAS PELAYANAN TERHADAP KEPUASAN PASIEN DI RSUD MOROWALI KECAMATAN BUNGKU TENGAH
}

\author{
Adriansyah \\ Syamsul Bahri \\ Ira Nuriya Santi \\ Program Studi S1 Manajemen Fakultas Ekonomi Universitas Tadulako \\ E-mail: iyanbureges54@gmail.com
}

\begin{abstract}
This study aims to determine and analyze the influence of service quality consisting of Physical Evidence, Empathy, Reliability, Responsiveness and Guarantee to patient satisfaction In Morowali District Hospital Central Bungku. The problem in this research is whether the service quality consisting of Physical Evidence, Empathy, Reliability, Responsiveness and Guaranteed simultaneously and partially have a significant effect on patient satisfaction In Morowali District Hospital of central Bungku. Based on that opinion, the sample size is 15 (5 1) 15 (6) 90. To prove the hypothesis, the research use multiple regression analysis. From the results of the study found that simultaneously the quality of service significantly influence patient satisfaction In Morowali District Hospital Central Bungku. This means that the variables of Physical Evidence, Empathy, reliability, partially significant effect on patient satisfaction variable, name Response Power and Assurance partially have no significant effect on patient satisfaction.
\end{abstract}

\section{Keywords: Service Quality Patient, Satisfaction}

\begin{abstract}
Abstrak
Penelitian ini bertujuan mengetahui dan menganalisis pengaruh kualitas pelayanan yang terdiri atas Bukti Fisik, Empati, Kehandalan, Daya Tanggap dan Jaminan terhadap kepuasan pasien Di RSUD Morowali Kecamatan Bungku Tengah. Permasalahan dalam penelitian ini adalah apakah kulitas pelayanan yang terdiri dari Bukti Fisik, Empati, Kehandalan, Daya Tanggap dan Jaminan secara simultan dan parsial berpengaruh signifikan terhadap kepuasan pasien Di RSUD Morowali Kecamatan Bungku Tengah. Berdasarkan pendapat tersebut maka besar sampel adalah $15(5+1) 15$ (6) 90. Untuk membuktikan Hipotesis tersebut, penelitian menggunakan analisis regresi berganda. Hasil penelitian ditemukan bahwa secara simultan kualitas pelayanan berpengaruh signifikan terhadap kepuasan pasien Di RSUD Morowali Kecamatan Bungku Tengah. Artinya variabel Bukti Fisik, Empati, kehandalan, secara parsial berpengaruh signifikan terhadap variabel kepuasan pasien, namaun Daya Tanggap dan Jaminan secara parsial tidak mempunyai pengaruh signifikan terhadap kepuasan pasien.
\end{abstract}

Kata Kunci: Kualitas Pelayanan, Kepuasan Pasien

\section{PENDAHULUAN}

Persaingan industri jasa kesehatan saat ini sangat ketat. Hal ini disebabkan semakin banyaknya jumlah klinik dan rumah sakit yang ada, serta semakin banyaknya masyarakat menggunakan fasilitas rumah sakit untuk memperoleh layanan kesehatan. Rumah sakit yang awalnya lebih banyak merupakan suatu unit pelayanan publik yang bersifat sosial kemanusiaan, secara faktual pelayanan rumah sakit dan organisasi pelayanan kesehatan telah mengalami transformasi (perubahan) serta berkembang menjadi suatu industri berbasis pada prinsip-prinsip ekonomi dan manajeman layaknya usaha komersil. Namun yang paling terpenting dalam industri jasa kesehatan (Rumah Sakit) adalah kualitas pelayanan yang diberikan pihak rumah sakit kepada pasien.

Untuk meningkatkan kualitas jasa kesehatan ,kualitas pelayanan dan kepuasan pasien menjadi indikator keberhasilan penyelenggaraan pelayanan di rumah sakit. Karena kualitas pelayanan sangat penting sebagai upaya pemenuhan kebutuhan dan keinginan pelanggan serta ketetapan 
penyampaiannya untuk mengimbangi harapan pelanggan (Simamora, 2003:180) dan dengan kualitas pelayanan yang baik pasien akan merasa puas (pelayanan sesuai dengan yang diharapkan). Namun pada dasarnya kualitas pelayanan yang baik tidak cukup hanya dicapai, tetapi juga dipelihara dan dipertahankan mengingat adanya pergeseran kebutuhan, harapan, dan keinginan pelanggan dan berbagai pihak yang berkepentingan. Untuk itu, RSUD Morowali sebagai industri jasa kesehatan yang menjadi satu-satunya rumah sakit yang ada di Kabupaten Morowali diharapkan dapat memberikan pelayanan yang lebih berkualitas dan konsisten. Kuncinya adalah memenuhi atau melebihi harapan kualitas pelayanan pasien, sehingga dapat menciptakan loyalitas pelanggan.

Namun disisi lain, bentuk pelayanan yang berkembang saat ini membuat kualitas pelayanan menjadi sangat rumit dan sulit diukur, karena hasil yang terlihat merupakan resultante dari berbagai faktor yang berpengaruh. Oleh sebab itu, untuk mencapai kualitas pelayanan yang baik memerlukan upaya dari berbagai pihak, dalam hal ini kerjasama dari setiap unit yang mengambil peran sangat penting.

Industri jasa kesehatan, kepuasan pasien merupakan nilai subyektif terhadap kualitas pelayanan yang diterima oleh pasien.Meskipun nilai subyektif ini sangat dipengaruhi oleh pengalaman masa lalu, pendidikan, keadaan emosional dan lingkungan pasien. Kepuasan pasien akan tetap didasari oleh kenyataan yang obyektif yang dialami pasien pada saat menerima palayanan dirumah sakit. Kepuasan itu sendiri menurut Kotler et al (2004:42) adalah perasaan senang atau kecewa seseorang yang muncul setelah membandingkan antara persepsi/kesannya terhadap kinerja (atau hasil) suatu produk dan harapan-harapan. Pasien yang puas merupakan asset yang sangat berharga karena apabila pasien puas mereka akan terus melakukan pemakaian terhadap jasa pilihanya, tetapi jika pasien tidak puas maka pasien tidak akan menggunakan jasa tersebut dan akan memberitahukannya kepada konsumen lain. Oleh sebab itu, untuk menciptakan kepuasan pasien perusahaan jasa kesehatan (rumah sakit) harus menciptakan dan mengelola suatu sistem untuk memperoleh pasien yang lebih banyak dan mampu untuk mempertahankan pasiennya. Hal ini didukung dengan kutipan yang diambil dari Simamora (2003:186), ada lima dimensi yang dipergunakan konsumen untuk menilai atau menentukan kualitas pelayanan. Kelima dimensi tersebut meliputi:

1. Keandalan (realibility) adalah kemampuan memberikan pelayanan sebagaimana yang telah dijanjikan secara akurat.

2. Bukti langsung (tangible) merupakan penampilan dari fasilitas fisik, peralatan, karyawan, sarana komunikasi yang dimiliki perusahaan.

3. Daya tanggap (responsiveness) adalah kesediaan karyawan untuk memberikan bantuan dan menjawab permasalahan yang dihadapi pelanggan.

4. Jaminan (assurance) Assurance adalah kemampuan dari pengetahuan dan kejujuran karyawan dalam membengkitkan kepercayaan pelanggan.

5. Empati (empathy) berkaitan dengan kemampuan karyawan memberikan perhatian yang khusus kepada pelanggan.

Perlu di cermati organisasi atau manajemen rumah sakit tidak akan berjalan tanpa peran penting dari beberapa pihak yang bekerjasama didalamnya. Salah satunya perawat. Perawat merupakan suatu profesi yang membantu rumah sakit dalam meningkatkan kualitas pelayanan untuk menciptakan kepuasan. Dimana sikap profesional perawat memberikan perasaan nyaman, terlindungi pada diri pasien yang sedang menjalani rawat inap (proses penyembuhan) dan diharapkan dapat menimbulkan perasaan puas pada diri pasien.

Fenomena yang terjadi di RSUD Kabupaten Morowali adalah pasien yang datang berobat untuk mendapatkan pelayanan maupun yang sudah mendapatkan pelayanan kesehatan setiap hari tidak selalu sama atau berbeda-beda terutama pada pasien. Setiap pasien yang datang berkunjung di rumah sakit tersebut masing-masing memiliki kesan, baik itu kesan yang menggambarkan bahwa pasien puas atau tidak puas terhadap pelayanan yang diberikan oleh pihak rumah sakit. 


\section{KAJIAN LITERATUR DAN PENGEMBANGAN HIPOTESIS}

Setiap aktifitasnya, pemasaran merupakan tulang punggung bagi kemajuan suatu usaha. Oleh karena itu berbagai upaya dilakukan dalam bidang pemasaran agar mampu menarik pembeli/pemakai jasa untuk menggunakan barang/jasa yang dihasilkan. Hal ini berarti peran pemasaran menjadi sangat penting dan akan berpengaruh secara langsung terhadap kegiatan pengembangan diri dan kehandalan laba.

Perkembangan ilmu pemasaran, banyak ahli pemasaran yang mengemukakan pendapat serta pandangan mereka mengenai pemasaran. Namun demikian pada prinsipnya kesemuanya mempunyai pengertian yang hampir samayaitu dengan cara bagaimana suatu produk yang telah disiapkan oleh para produsen akan tersalurkan pada waktu yang tepat dan konsumen mendapatkan kepuasann didalam penggunanya sesuai dengan pengorbanan yang diberikan. Untuk lebih jelasnya, maka berikut ini penulis akan mengutip beberapa pendapat/definisi tentang pemasaran yang dikemukakan oleh beberapa ahli dalam bidang pemasaran seperti:

Pengertian Pemasaran menurut Kotler dan Keller (2012:478) adalah kegiatan dan program online yang dirancang untuk melibatkan pelanggan atau prospek dan secara langsung atau tidak langsung meningkatkan kesadaran, memperbaiki citra, atau menciptakan penjualan produk dan jasa. Pemasaran menurut Sunarto (2006:4) adalah proses sosial yang di dalamnya individu dan kelompok mendapatkan apa yang dibutuhkan dan diinginkan dengan menciptakan, menawarkan, dan mempertukarkan produk yang bernilai dengan pihak lain.

Pemasaran menurut Miller et al (2004:2) adalah sistem total aktivitas bisnis yang dirancang untuk merencanakan, menetapkan harga, mempromosikan dan mendistribusikan produk, jasa dan gagasan yang mampu memuaskan keinginan pasar sasaran dalam rangka mencapai tujuan organisasional. Berdasarkan definisi di atas dapat disimpulkan bahwa pemasaran merupakan serangkaian aktifitas untuk mengidentifikasi kebutuhan dan keinginan pasar, agar produk atau jasa yang ditawarkan dapat diterima dan disenangi oleh pasar.

Kata kualitas mengandung banyak definisi dan makna karena orang yang berbeda akan mengartikannya secara berlainan, seperti kesesuaian dengan persyaratan atau tuntutan, kecocokan untuk pemakaian perbaikan berkelanjutan, bebas dari kerusakan atau cacat, pemenuhan kebutuhan pelanggan, melakukan segala sesuatu yang membahagiakan. Pada persepektif TQM (Total Quality Management) kualitas dipandang secara lebih luas, yaitu tidak hanya aspek hasil yang ditekankan, tetapi juga meliputi proses, lingkungan dan manusia.

Menurut Simamora (2003:180) ada dua faktor yang mempengaruhi kualitas pelayanan yaitu expected service dan perceived service. Apabila pelayanan yang diterima atau dirasakan sesuai dengan yang diharapkan, maka kualitas pelayanan dipersepsikan baik dan memuaskan. Berdasarkan beberapa pengertian kualitas di atas dapat diartikan bahwa kualitas hidup kerja harus merupakan suatu pola pikir (mindset), yang dapat menterjemahkan tuntutan dan kebutuhan pasar konsumen dalam suatu proses manajemen dan proses produksi barang atau jasa terus menerus tanpa hentinya sehingga memenuhi persepsi kualitas pasar konsumen tersebut.

Kulaitas memiliki hubungan yang sangat erat dengan kepuasan pelanggan, yaitu kualitas memberikan suatu dorongan kepada pelanggan untuk menjalani ikatan hubungan yang kuat dengan perusahaan, dalam jangka panjang ikatan seperti ini memungkinkan perusahaan untuk memahami dengan saksama harapan pelanggan serta kebutuhan mereka, dengan demikian perusahaan dapat meningkatkan kepuasan pelanggan yang pada gilirannya kepuasan pelanggan dapat menciptakan kesetiaan atau loyalitas pelanggan kepada perusahaan yang memberikan kualitas memuaskan.

Kualitas layanan merupakan pelayanan terbaik yang dilakukan oleh seseorang, kelompok atau lembaga yang memberi kepuasan bagi pelanggan atau masyarakat dan pada gilirannya kepuasan itu akan menciptakan loyalitas pelanggan atau masyarakat kepada seseorang/kelompok/lembaga yang 
memberikan pelayanan tersebut. Pelayanan kesehatan sebagai spesifikasi dari pelayanan publik itu sendiri menurut (Levey, et al (2010) Menjelaskan dalam bentuknya bahwa jenis pelayanan kesehatan bermacam-macam, dalam pengklarifikasinya dapat di tentukan dengan tiga hal berikut.

1. Pengoprasian pelayanan. Dapat dilaksanakan secara sendiri atau bersama-sama dalam suatau organisasi.

2. Ruang lingkup kegiatan. Dapat mencangkup kegiatan pemeliharaan kesehatan, pemulihan kesehatan, atau kombinasi dari padanya.

3. Sasaran pelayanan kesehatan. Dapat ditunjukan untuk proses keluarga, kelompok, ataupun untuk masyarakat secara keseluruhan.

Secara sederhana ada tiga persyaratan pokok yang harus dimiliki untuk disebut pelayanan kesehatan yang baik (Muninjaya, 2011), yaitu:

1 sesuai dengan kebutuhan pemakian jasa pelayanan. Suatu pelayanan kesehatan yang baik adalah sesuai dengan kebutuhan pemakai jasa pelayanan.

2 Dapat dijangkau oleh mereka yang membutuhkan. Pengertian terjangkau disini adalah tidak hanya dari sudut jarak atau lokasi tetapi juga dari sudut pembiayaan.

Sesuai dengan prinsip ilmu dan tekhnologi kedokteran, dengan kata lain suatu pelayanan kesehatan yang baik adalah pelayanan kesehatan yang terjamin mutunya. Kotler dan keller 2009 mengemukakan bahwa tingkat kepuasan adalah: "Satisfaction is a person's feelings of pleasure or disappointment resulting from comparing a product's percieved performance (or outcome) in relation to his or her expectations." Artinya, kepuasan adalah perasaan senang atau kecewa seseorang yang muncul setelah membandingkan antara persepsi/kesannya terhadap kinerja (atau hasil) suatu produk dan harapan-harapannya. Sukar untuk mengukur tingkat kepuasan pasien, karena menyangkut perilaku yang sifatnya sangat subyektif. Kepuasan seseorang terhadap suatu obyek bervariasi mulai dari tingkat sangat puas, puas, cukup puas, kurang puas, sangat tidak puas.

Harapan konsumen terhadap kualitas pelayanan sangat dipengaruhi oleh informasi yang diperolehnya dari mulut ke mulut, kebutuhan-kebutuhan konsumen itu sendiri. Kepuasan pasien mempunyai peranan penting dalam perkiraan kualitas pelayanan rumah sakit.Kepuasan dapatdianggap sebagai pertimbangan dan keputusan penilaian pasien terhadap keberhasilan pelayanan (Donabedian,2000:96).Kepuasan pasien adalah salah satu ukuran kualitas pelayanan perawatan dan merupakan alat yang dapat dipercaya dalam membantu menyusun suatu perencanaan,pelaksanaan dan evaluasi dari sistem pelayanan di rumah sakit.

Menurut Utama (2005:5) indikator pelayanan kesehatan yang dapat menjadi prioritas menentukan kepuasan pasien, diantaranya adalah seperti berikut:

1. Kinerja tenaga dokter, adalah prilaku atau penampilan dokter rumah sakit dalam proses pelayanan kesehatan pada pasien, yang meliputi ukuran: layanan medis, layanan nonmedis, tingkat kunjungan, sikap,dan penyampaian informasi.

2. Kinerja tenaga perawat, adalah perilaku atau penampilan tenaga perawat rumah sakit dalam proses pemberian pelayanan kesehatan pada pasien, yang meliputi ukuran: layanan medis, layanan non medis,sikap, penyampaian informasi, dan tingkat kunjungan.

3. Kondisi fisik, adalah keadaan sarana rumah sakit dalam bentuk fisik seperti kamar rawat inap, jendela, pengaturan suhu, tempat tidur, kasur dan sprei.

4. Makanan dan menu, adalah kualitas jenis atau bahan yangdimakan atau dikonsumsi pasien setiap harinya, seperti nasi, sayuran,ikan, daging, buah-buahan,dan minuman. Menu makanan adalah pola pengaturan jenis makanan yang dikonsumsi oleh pasien.

5. Sistem administrasi pelayanan, adalah proses pengaturan atau pengelolaan pasien di rumah sakit yang harus diikuti oleh pasien (rujukan dan biasa), mulai dari kegiatan pendaftaran sampai pasien rawat inap. 
6. Pembiayaan, adalah sejumlah uang yang harus dibayarkan kepada rumah sakit selaras pelayanan yang diterima oleh pasien, seperti biaya dokter, obat-obatan, makan, dan kamar.

7. Rekam medis, adalah catatan atau dokumentasi mengenai perkembangan kondisi kesehatan pasien yang meliputi diagnosis perjalanan penyakit, proses pengobatan dan tindakan medis, dan hasil pelayanan.

Penilaian terhadap kualitas pelayanan kesehatan sangat penting, sebab dapat digunakan untuk menilai seberapa jauh pelayanan yangdiberikan oleh organisasi memenuhi harapan dan memuaskan penggunajasa. Menurut Dwiyanto (2002: 47) penilaian kualitas pelayanan publik tidak cukup hanya dilakukan dengan menggunakan indikator-indikator yang melekat pada birokrasi/petugas seperti efisiensi dan efektivitas, tetapi harus dilihat juga dari indikator-indikator yang melekat pada pengguna jasa, seperti kepuasan pengguna jasa, akuntabilitas, dan responsivitas.

Berdasarkan pada permasalahan, landasan teori dan kerangka pemikiran diatas, maka penelitian mengajukan hipotesis sebagai kerangka acuan dalam penelitian ini sebagai berikut:

a. Kualitas pelayanan yang terdiri atas Bukti Fisik (Tangibles), Empati (Empathy), Kehandalan (Reliability), Daya Tanggap (Responsivenss) dan Jaminan (Assurance) secara serempak berpengaruh signifikan terhadap kepuasan pasien Di RSUD Morowali Kecamatan Bungku Tengah?

b. Variabel Bukti Fisik (Tangibles) secara parsial berpengaruh signifikan terhadap kepuasan pasien Di RSUD Morowali Kecamatan Bungku Tengah?

c. Variabel Empati (Empathy) secara parsial berpengaruh signifikan terhadap kepuasan pasien Di RSUD Morowali Kecamatan Bungku Tengah?

d. Variabel Kehandalan (Reliability) secara parsial berpengaruh signifikan terhadap kepuasan pasien Di RSUD Morowali Kecamatan Bungku Tengah?

e. Variabel Daya Tanggap (Responsivenss) secara parsial berpengaruh signifikan terhadap kepuasan pasien Di RSUD Morowali Kecamatan Bungku Tengah?

f. Variabel Jaminan (Assurance) secara parsial berpengaruh signifikan terhadap kepuasan pasien Di RSUD Morowali Kecamatan Bungku Tengah?

\section{METODE PENELITIAN}

Penelitian ini di kategorikan sebagai deskriptif dan kausalitas, yaitu penelitian yang menjelaskan pengaruh kausal antara variabel-variabel penelitian melalui pengujian hipotesis (Suliyanto, 2006).Unit analisis dalam penelitian ini adalah pasien rawat inap pada RSUD Morowali di Kecamatan Bungku Tengah.

\section{Lokasi dan Waktu Penelitian}

Lokasi penelitian adalah di RSUD Morowali Kecamatan Bungku Tengah, dan waktu penelitian selama 2 bulan. Peneliti mengambil lokasi penelitian pada Rumah Sakit Umum Daerah Morowali karena ingin menganalisis tentang kepuasan pasien terhadap pelayanan yang telah diberikan oleh para petugas medis Rumah Sakit Umum Daerah Morowali kepada pasien yang datang berobat.

\section{Metode Pengumpulan Data}

Pengumpulan data adalah prosedur sistematis dan standar untuk memperoleh data yang diperlukan dan memiliki hubungan antara metode pengumpuan data dengan penelitian yang ingin dilaksanakan. Tanpa mengetahui teknik pengumpulan data, maka peneliti tidak akan mendapatkan data yang memenuhi standar data yang ditetapkan. 


\section{Analisi Linear Berganda}

Metode analisis yang digunakan dalam penelitian ini adalah Metode Analisis Kuantitatif, metode ini digunakan untuk menganalisis data yang memerlukan pengukuran kuantitatif dengan menggunakan analisis statistik. Analisis statistik yang digunakan dalam penelitian ini adalah analisis regresi berganda yang diolah dengan program software SPSS 16,0. Analisis regresi berganda digunakan untuk mengetahui seberapa besar pengaruh kualitas layanan terhadap kepuasan pasien rawat inap. Model Regresi Berganda terdapat variabel independen X1, X2, .. Xn, dengan variabel dependen $\mathrm{Y}$, maka secara hubungan linear diformulasikan sebagai berikut:

$$
\mathrm{Y}=\alpha+\quad+\ldots \ldots \ldots \ldots . .++
$$

Dimana:

$\mathrm{Y}=$ variabel terikat (dependen variabel)

- = variabel bebas (independen variabel)

$\alpha \quad=$ konstanta (intercept)

$=$ koefisien regresi

$=$ kesalahan pengganggu

Formulasi di atas, jika dimasukan kedalam variabel penelitian maka dapat diperoleh persamaan regresi berganda sebagai berikut:

$$
\mathrm{Y}=\alpha++++++
$$

Dimana:

$$
\begin{aligned}
\mathrm{Y} & =\text { Kepuasan Pasien } \\
\alpha \quad & =\text { Konstanta } \\
& =\text { Bukti Fisik } \\
& =\text { Empati } \\
& =\text { Kehandalan } \\
& =\text { Daya Tanggap } \\
& =\text { Jaminan } \\
,,,, & =\text { Koefisien Regresi } \\
& =\text { error (faktor penggangu) }
\end{aligned}
$$

Nilai regresi dari masing-masing variabel diperoleh berdasarkan metode kuadrat terkecil merupakan estimator terbaik atau best liner unbiased estimator (BLUE).

\section{HASIL DAN PEMBAHASAN}

\section{Uji Normalitas}

Uji normalitas digunakan untuk menguji apakah dalam model regresi, kedua variabel (bebas maupun terikat) mempunyai distribusi normal atau setidaknya mendekati normal. Pada prinsipnya normalitas dapat di dekati dengan melihat penyebaran data (titik) pada sumbu diagonal dari grafik atau dengan melihat histogram dari residualnya. Dasar pengambilan keputusan adalah 


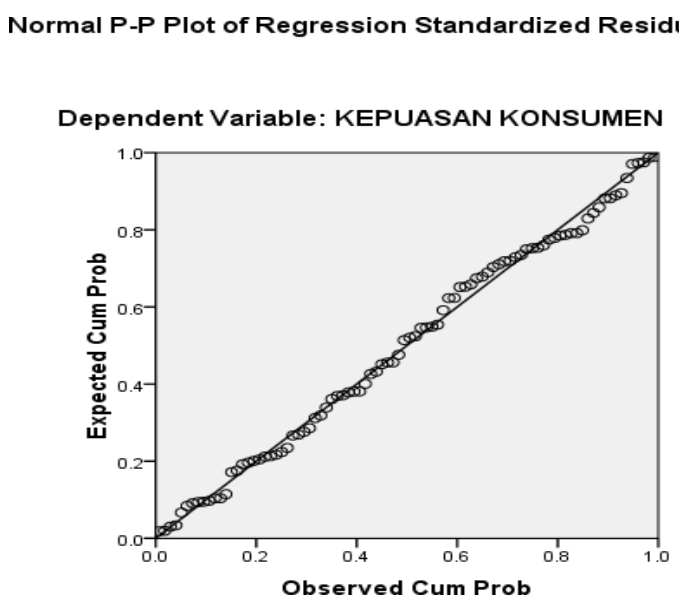

Gambar 1

Gambar 1 menunjukan bahwa distribusi normal yang ditunjukan pada titik-titik yang menyebar dan penyebarannya mengikuti arah garis diagonal sehingga dapat disimpulkan model regresi mengikuti asumsi normalitas.

\section{Uji Heteroskedastistisitas}

Uji heteroskedastisitas adalah untuk menguji apakah dalam model regresi terjadi ketidaksamaan varians dari residual satu pengamatan ke pengamatan yang lain. Jika varians dari residual satu ke pengamatan dan ke pengamatan lain tetap, maka disebut heteroskedastisitas dan jika varians berada disubut heteroskedastisitas. Model regresi yang baik adalah yang homokedastisitas atau heteroskedastisitas (Ghozali, 2005:211).

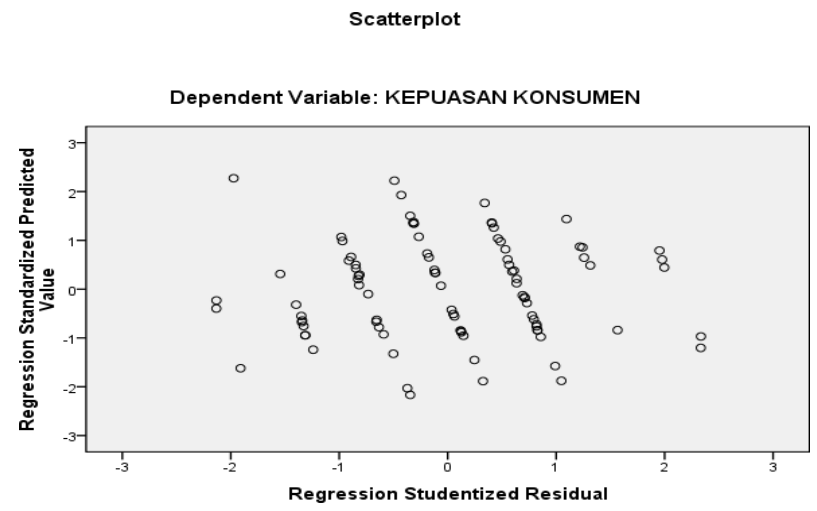

Gambar 2

Berdasarkan gamabar 2 di atas terlihat bahwa tidak ada pola yang jelas, serta titik-titik menyebar diatas dan dibawah angka 0 pada sumbu $\mathrm{Y}$, dengan demikian modal regresi diatas memenuhi asumsi homogenitas atau tidak terjadi heterokedastisitas. Pola yang terbentuk dapat pula diartikan bahwa kepuasan konsumen berbeda-beda atau tidak sama antara konsumen satu dengan lainnya. 
Tabel 1

Pengujian Hipotesis Pertama ( Uji F )

\begin{tabular}{|ll|l|l|}
\hline Model & F & Sig. \\
\hline 1 & Regression & 11.651 & $.000^{\mathrm{a}}$ \\
& Residual & & \\
& & \\
\hline
\end{tabular}

Berdasarkan tabel 1 di atas, dimana hipotesis peratama disebutkan bahwa kualitas pelayanan yang terdiri dari bukti fisik, empaty, kehandalan, daya tanggap. Jaminan secara simultan berpengaruh signifikan terhadap kepuasan pasien RSUD Morowali kecamatan bungku tengah. Hasil F hitung di peroleh sebesar 11,651 pada taraf nyata $\alpha=0,05$ atau F. Sig $<0,05$. Tabel tersebut menunjukan bahwa nilai signifikan $F=0,000^{a}$. Hubungan kualitas dan kepuasan dapat dinayatakan bahwa secara bersama-sama variabel kualitas layanan berpengaruh signifikan terhadap kepuasan pasien RSUD Morowali Kecamatan Bungku Tengah.

Tabel 2

Pengujian hipotesis kedua (Uji t)

\begin{tabular}{|c|c|c|c|}
\hline \multicolumn{2}{|c|}{ Model } & \multirow{2}{*}{$\frac{\mathrm{T}}{3.058}$} & \multirow{2}{*}{$\frac{\text { Sig. }}{.003}$} \\
\hline 1 & (Constant) & & \\
\hline & BUKTI FISIK & 1.372 & .004 \\
\hline & EMPATI & 1.672 & .045 \\
\hline & KEHANDALAN & 1.221 & .025 \\
\hline & DAYA TANGGAP & 2.895 & .073 \\
\hline & JAMINAN & 2.165 & .069 \\
\hline
\end{tabular}

Pengujian terhadap pengaruh masing-masing variabel independen terhadap variabel dependen disebut uji parsial ( Uji-t). Uji parsial pada fungsi estimasi bertujuan untuk membuat kesimpulan mengenai perngaruh masing-masing variabel independen $(\mathrm{X})$ terhadap variabel dependen $(\mathrm{Y})$. Uji $\mathrm{t}$ dilakukan dengan membandingkan nilai $t$ sig dengan nilai $\alpha$. Jika probalilitas $t \operatorname{sig}<\alpha(0,05)$ maka terdapat pengaruh signifikan. 
Tabel 3

Hasil Perhitungan Regresi Berganda (SPSS)

\begin{tabular}{|c|c|c|c|c|}
\hline \multicolumn{5}{|c|}{ Dependen Variabel Y = Kepuasan Pasien } \\
\hline Variabel & $\begin{array}{c}\text { Koefisien Regresi } \\
(\mathbf{B})\end{array}$ & Standar Error & $\mathbf{T}$ & Sig \\
\hline (Constata) & 2,920 &, 955 & 3,058 &, 003 \\
\hline Bukti Fisik &, 164 &, 120 & 1,372 &, 004 \\
\hline Empati &, 066 &, 099 & 1,672 &, 045 \\
\hline Kehandalan &, 023 &, 103 & 1,221 &, 025 \\
\hline Daya Tanggap &, 103 &, 115 & 2,895 &, 073 \\
\hline Jaminan &, 025 &, 149 & 2,165 &, 069 \\
\hline $\mathrm{R} \quad 0,193$ & & F - hitung $=11,651$ \\
\hline $\mathrm{R}-$ Square $=0,037$ & $=0$ & Sig. F $=0,000^{\mathrm{a}}$ \\
\hline
\end{tabular}

$$
Y=2,920+0,164 X_{1}+0,066 X_{2}+0,023 X_{3}+0,103 X_{4}+0,025 X_{5}+e
$$

\section{KESIMPULAN DAN SARAN}

Kesimpulan

Berdasarkan hasil pembahsan penelitian yang telah dikemukakan diatas, maka penulisan dapat mengambil beberapa kesimpulan dari hasil penilian sebagai berikut:

1. Kualitas pelayanan yang terdiri atas bukti fisik, empaty, kehandalan, daya tanggap dan jaminan secara simultan berpengaruh signifikan terhadap kepuasan pasien di RSUD Morowali Kecamatan Bungkuh Tengah.

2. Bukti fisik secara parsial berpengaruh signifikan terhadap kepuasan pasien di RSUD Morowali Kecamatan Bungkuh Tengah.

3. Empati secara parsial berpengaruh signifikan terhadap kepuasan pasien di RSUD Morowali Kecamatan Bungku Tengah.

4. Kehandalan secara parsial berpengaruh signifikan terhadap kepuasan pasien di RSUD Morowali Kecamatan Bungku Tengah.

5. Daya tanggap secara parsial tidak berpengaruh signifikan terhadap kepuasan pasien RSUD Morowali Kecamatan Bungkuh Tengah.

6. Jaminan secara parsial tidak berpengaruh signifikan terhadap kepuasan pasien RSUD Morowali Kecamatan Bungku Tengah.

\section{Saran}

hasil kesimpulan yang telah dijelaskan, maka disarankan sebagai berikut:

1. Disarankan kepada RSUD Morowali agar dalam memberikan pelayanan kepada pasien, hendaknya tetap memperhatikan faktor - faktor dimensi pelayanan yang meliputi bukti 
fisik, empati, kehandalan, daya tanggap dan jaminan dalam melakukan pelayanan kepada pasien.

2. Mengingat bahwa variabel kehandalan merupakan variabel yang paling dominan, maka disarankan kepada pihak RSUD Morowali agar memperhatikan ketepatan waktu dalam memberi pelayanan, dan antrian pelayanan rumah sakit yang tertip.

3. Unsur Pelayanan yang menjadi proritas utama untuk lebih meningkatkan kulitas pelayanan adalah kejalasn petugas pelayanan, kedisiplinann petugas pelayanan, dan keadilan mendapatkan pelayanan.

\section{REFERENSI}

Donabedian, A. 2000. Exprolation in Quality Assesment and Monitoring. Arbor Michinga: Health Administration Press.

Dwiyanto, A. 2002. Reformasi Briokrasi Publik di Indonesia. Yogyakarta: Pusat Studi Kependudukan UGM.

Ghozali, I, 2005. Metode Penelitian Bisnis, Bagian Penerbitan FE-UNDIP, Semarang.

Kotler, Philip., dan Gary Armstrong., 2004. Dasar-dasar Pemasaran. Edisi kesembilan, Jilid 2, diahlibahasakan oleh Alexander Sindoro. Jakarta: Indeks

Kotller dan Keller, 2009, Manajemen Pemasaran. Jilit I. Edisi ke 13 Jakarta:Erlangg.

Kotler dan keller (2012:478) Manajemen Pemasaran. Edisi 12. Jakarta: Erlanga

Miller, R.L., I. Tegan, and J.P. Perwitz, 2004: Surface radiative forcing by soil dust aerosols and the hydrologic cycle. J. Geophys. Res., 109, D04203, doi: 10.1029/2013JD004085.

Muninjaya, Gde AA, 2011, Manajemen Mutu Pelayanan Kesehatan, Jakarta, EGC

Simamora, Bilson, 2003, Membongkar Kotak Hitam Konsumen, Jakarta:Gramedia Pustaka Utama. Sunarto, (2006:4). Penegrtian Manajemen, Bandung: CV Alfabeta

Suliyanto, 2006. Metode Riset Bisnis. Yogyakarta.Andi.

Utama, S. 2005. "Memahami Fenomena Kepuasan Pasien Rumah Sakit". Jurnal Manjemen

Kesehatan. 09(1), 1-7 
